Nitsshe, F. (2007) Tak govoril Zaratustra. Moscow, Kul'turnaia revoliutsiia. 432 p. (In Russ.).

Ortega-i-Gasset, Kh. (1991) Vosstanie mass. In: Estetika. Filosofiia kul'tury / ed. by G. M. Fridlendera ; comp. by V. E. Bagno. Moscow, Iskusstvo. 588 p. Pp. 309-350.

Prokof'ev, V. (1983) O trekh urovniakh khudozhestvennoi kul'tury Novogo i Noveishego vremeni: probleme primitiva v izobrazitel'nom iskusstve. In: Primitivi ego mesto v kul'ture Novogo $i$ Noveishego vremeni / ed. by V. N. Prokof'ev. Moscow, Nauka. 205 p. Pp. 6-28. (In Russ.).

Khrenov, N. A. (1988) Zrelishchnye formy kul'tury i massovaia publika. In: Zrelishchnye iskusstva. Obzornaia informatsiia. Vol. 2. Moscow, NIO Informkul'tura. 36 p. Pp. 15-16. (In Russ.).

Shopengauer, A. (2011) Mir kak volia i predstavlenie. Minsk, Kharvest. 848 p. (In Russ.). $221 \mathrm{p}$.

Iastrebova, N. A. (1984) Individual'noe i massovoe v sovetskom iskusstve. Moscow, Nauka.

Submission date: 12.09.2019.

Костина Анна Владимировна - доктор философских наук, доктор культурологии, професcop, директор Института фундаментальных и прикладных исследований, заведующий кафедрой философии, культурологии и политологии Московского гуманитарного университета. Aдрес: 111395, Россия, г. Москва, ул. Юности, А. 5. Тел.: +7 (499) 374-75-95. Эл. адрес: Anna_Kostina@inbox.ru

Kostina Anna Vladimirovna, Doctor of Philosophy, Doctor of Culturology, Professor, Director, Institute of Fundamental and Applied Studies; Head, Department of Philosophy, Culturology and Politology, Moscow University for the Humanities.Postal address: 5, Yunosti St., Moscow, Russian Federation, 111395.Tel.: +7 (499) 374-61-81.E-mail: Anna_Kostina@inbox.ru

DOI: $10.17805 / z p u .2019 .4 .24$

\title{
Фундамент тезаурусной социологии
}

\author{
И. А. ПОЛУЭХТОВА
}

МОСКОВСКИЙ ГОСУДАРСТВЕННЫЙ УНИВЕРСИТЕТ ИМ. М. В. ЛОМОНОСОВА

Рецензия на издание: Луков, В. А. Тезаурусная социология : в 4 т. М. : Изд-во Моск. гуманит. ун-та, 2018.

Ключевые слова: рецензия; теория социологии; тезаурусный подход

B 2018 г. один за другим в издательстве Московского гуманитарного университета вышли четыре тома монографии В. А. Аукова «Тезаурусная социология» (Ауков, $2018 \mathrm{abcd})$. Многие годы в социологических исследованиях он применял тезаурусный подход, детально разработанный им и его братом, видным культурологом и литературоведом Вл. А. Ауковым (1948-2014). Этот подход нашел применение и получил «порт приписки» во многих гуманитарных и социальных науках - философии, психологии, культурологии, филологии, политологии, антропологии, а также в таких сложных предметных областях социальных наук, как биоэтика, социальное проектирование, социализация и др. (Ауков В., Ауков Вл., 2008, 2013, 2014). Благодаря В. А. Аукову он стал активно использоваться в социологии молодежи. 
Аостоинства тезаурусного подхода как одного из вариантов субъектно-ориентированной методологии подчеркивали Б. Г. Юдин, Т. Ф. Кузнецова, А. В. Костина, Ч. К. Аамажаа (Юдин, 2005; Кузнецова, 2014; Костина, 2008; Аамажаa, 2013), о его применимости к образовательным программам писал И. С. Болотин (Болотин, 2009), о пользе опоры на него в социологических исследованиях, включении в процесс критическиконструктивного осмысления постмодернизма в социологии, применении в социологии молодежи - Ю. А. Зубок и В. И. Чупров, А. И. Ковалева и В. Ф. Аевичева, С. И. Григорьев (Чупров, Зубок, 2011; Ковалева, Аевичева, 2012/2013; Григорьев, 2010). На тезаурусный подход и его деривации в философии и социологии опирались Ю. В. Болтенкова, А. А. Агранат, Э. К. Погорский, В. А. Аапшин (Болтенкова, 2011, Агранат, 2010, Погорский, 2013; Аапшин, 2013) и многие другие ученые - признанные в научных сообществах и начинающие. Можно определенно сказать, что этот подход воспринят немалым числом исследователей как продуктивный в сфере их научных поисков. Он стал одной из основ научной школы молодежных исследований МосГУ (Социология молодежи ..., 2018).

Но от перспективной методологии до новой конструкции социологии как науки значительный шаг. Аолжна быть определенная концепция предмета социологии и ее видение как целого. Здесь недостаточна только совокупность фрагментов, хоть и важных по отдельности, но не обладающих фундаментальностью общей теории общества. Надо учесть и то, что «общество» не должно пониматься абстрактно как нечто неизменное. Его типы интенсивно менялись и не обладают сходством несущих опор на протяжении веков. Связь присущих одним обществам черт социальной структуры, способов управления, культурных процессов может обнаруживаться в других обществах, а может быть лишь видимостью связи. В одних случаях побеждает линейный прогресс, в других - цикличность изменений, в третьих авторы исходят из того, что мир катится к катастрофе, к «концу истории»...

Что бы там ни было, концептуальность каждого из вариантов общей социологии их непременное свойство. Важные социологические идеи, высказанные в педологии $\Lambda$. С. Выготского, трактовке смеховой культуры М. М. Бахтина, системно-мыслительной методологии Г. П. Щедровицкого, семиотике Ю. М. Аотмана и во множестве других теорий, с разных сторон выявляющих особенные черты человека, культуры, общества, все же не означали (и не были нацелены на это) новых вариантов социологии. Выдающийся философ и филолог А. Ф. Аосев, например, еще в 1934 г. писал, что его курс истории эстетических учений строится на трех основных базах, среди которых «социологическая база является важнейшей и первостепенной...» (Иосев, 1995: 359). Однако это все же история эстетических учений, а не социология или какая-то из ее ветвей.

Иная картина складывается, когда перед читателем стоят четыре тома «Тезаурусной социологии» В. А. Аукова, а это 2436 страниц книжного текста. Суть замысла автором представлена во Введении к первому тому: «Тезаурусная социология - ракурс социологии, и, следовательно, опирается на общее понимание социологии как на научное представление в формах теории (теорий) и поддерживающих их (теорий) верность эмпирических исследований об обществе - в той его части, которая относится к зоне взаимодействия дюдей друг с другом, к людьми же созданным структурам (социальным структурам, социальным институтам и т. А.), но по законам отчуждения оторвавшимся от них и живущим далее от них независимо, а то и препятствующим их стремлениям, ожиданиям, порой неясным, но характеризующимся своей направленностью на изменения» (Иуков, 2018а: 3). 
152 печатных листа, которые занимает монография, не могли бы быть написаны в короткое время. Как указывает автор, монография составлена им из разделов книг, статей и фрагментов работ 1990-2010-х гг. (Ауков, 2018а: 22).Таким образом, это своеобразный свод сочинений, опубликованных за несколько десятилетий. Но не всех сочинений. В электронной библиографии «Валерий Андреевич Ауков: концепции и исследования. Научные публикации (1966-2018)» названы около 1300 его опубликованных работ (Валерий Андреевич Ауков ... , 2018), из них же выбраны те, которые в совокупности и создают облик тезаурусной социологии в аспектах ее методологии, свойств, структуры и специфики функционирования тезаурусов, а также вытекающих из этого конструкции и динамики становления общества. Размещение в томах издания выбранных статей, фрагментов и т. д. определяется не временем их написания и публикации, а логикой концепции тезаурусной социологии.

Эту логику отражает структура 4-томной монографии «Тезаурусная социология».

В первом томе автор раскрывает суть тезаурусов и методологию тезаурусного подхода в социологии. Его основное внимание сосредоточено на главной категории, которую составляет в предлагаемой версии социологии социальная субъектность. В переходных обществах особенно заметна ее роль, когда для классификации социальной структуры, социальных институтов и процессов невозможно опереться на фактор их устойчивости. Здесь социальная субъектность, понимаемая автором как «способность общества, сочиальных групп, человека выступать в качестве активного начала (деятеля, твориа) сочиальной реальности» (Ауков, 2018а: 317-318; курсив автора. - И. П.), позволяет охарактеризовать реальное общество как целое.

Но основу этого целого можно понимать по-разному. В. А. Ауков в качестве его ячейки представляет социальную общность (с ее теоретической трактовки начинается второй том монографии). Согласно его концепции, социальные общности преАставляют собой формы непосредственной или опосредованной сочиальной связи людей, возникающей в различных сегментах их жизнедеятельности (производство, распределение, потребление) на основе определенных ценностных ориентаций. «В качестве характерных черт социальных общностей следует рассматривать, во-первых, первоначальную неосознанность действий людей по их формированию. Этим трактовка социальной общности отличается от характеристики социальных организаций. Во-вторых, необходимо видеть, следовательно - и учитывать, близость условий жизни людей, составляюших обшность, в определенных направлениях и определенных пределах... Наконец, в-третьих, важно подчеркнуть значение отражения $b$ сознании принадлежности к обшности в спещифических формах тезауруса - как разделение “своих" и “чужих" " (Ауков, 2018b: 15; курсив автора. - И. П.). Как показывает В. А. Ауков, важнейшим структурообразующим компонентом социальной общности выступает идентификация. Она обеспечивает доступ механизмов и форм социальной регуляции к индивиду и освобождает индивида для деятельности в соответствии с освоенными ценностно-нормативными ориентирами в тех или иных ситуациях. Степень организованности социальных общностей, как и уровня идентификации с ними их членов, может быть и очень высокой, и едва заметной. Однако даже при низкой степени организованности и слабой идентификации в той или иной социальной общности она может быть выделена из социальной реальности и изучена как определенная целостность. При этом в разнообразных состояниях общества «всегда имеется достаточно много общностей, не являющихся для социальной структуры необходимыми 
элементами и не обладающими достаточно выраженными социальными функциями в смысле поддержания стабильности общества. Однако эти фрагменты социальной реальности не следует игнорировать в описаниях социальной структуры общества» (там же: 15-16).

В трактовке социальной общности видна опора на социальную субъектность, на особую роль конструирования своего культурного мира субъектом, что вытекает и из эмпирических исследований, проводившихся под руководством и с участием В. А. $\Lambda$ кова по крайней мере с конца 1980-х гг. Особенно интересны в этом плане исследования по беженцам и вынужденным переселенцам, выполненные в рамках качественной стратегии и обобщенные в теоретической идее «ко-биографии». Феномен ко-биографии позволяет «выявить собственно типические черты миграционного процесса не за счет усреднения данных, а путем выявления моделей реального поведения и реальной коммуникации» (там же: 59).

«Присвоение социальной субъектности»- так называется глава 4 монографии, занимающая весь третий том и значительную часть четвертого тома. Эта глава фактически строится как тезаурусная теория молодежи. Такой большой объем мог бы легко быть объяснен тем, что В. А. Ауков получил свою известность в социологии именно работами по молодежной тематике. Очевидно, что у него немало мыслей на этот счет и текстов, которые выражают концепцию книги. Но в действительности перекоса, который бы увлеченный автор не замечал, здесь нет.

Вот как в четвертом томе своей книги В. А. Ауков объясняет особое внимание к молодежи, молодежному движению, молодежной политике: «Молодежный аспект появился в тезаурусной социологии не только в силу того, что таково основное содержание научной школы молодежных исследований МосГУ... Аля тезауруса очень важно, что в период своего становления он подвижен, легко сочетает разные, порой по видимости противоположные тезаурусные генерации, за которыми просматриваются разные жизненные концепции как на уровне индивида, так и на уровне социальных общностей. Эта подвижность тезаурусов и одновременно высокий уровень включенности в социальные практики характерны для периода молодости, которому в современном обществе, какие бы названия ему ни давать, есть характеристики определенного социального слоя - молодежи. Свойства мерцающего тезауруса недолгие, исчерпаемые, имеющие разную глубину в зависимости прежде всего от исторических событий своего времени, ведущих к переориентации всех слоев общества (войны, революции и т. А.). Тезаурусная социология, может быть, случайно вышла на эту тему, но она оказалась центральной не только для нее, но и для обобщенного понимания общества в целом. Конечно, устойчивые образования, к которым относятся социальная структура, социальные институты, социальные практики, определяют специфику образа жизни людей, принадлежащих к разным поколениям; конечно, социальная идентификация позволяет увидеть целостность этого общества, его отличительные черты. Но как формируются эти устойчивые образования, как образуется эта идентификация, как они передаются от одного поколения к другому? Понять эти процессы можно, сосредоточив внимание на молодежи как переходе от детства с его неотрывной связью с нормами и ценностями старших поколений к взрослости, когда эта связь не нужна, поскольку взрослый человек сам носитель этих норм и ценностей. Переходность молодежи и означает присвоение той социальной субъектности, законным обладателем которой и выступают старшие. В этом сложном процессе, с приливами и отливами, конфликтностью, энтузиазмом молодости, ее бескомпромисснос- 
тью, происходит воспроизводство того общества, основные движущие силы которого скрыты для стороннего наблюдателя...» (Ауков, 2018d: 504-505).

Это объяснение многое проясняет. В аспекте становления и человека, и окружающего его мира в новом свете читаются описания теорий молодежи разных времен и разных стран, данные исследований в области биосоциологии и выводы из них, трактовки молодежного движения как освоения молодежью социальной субъектности, строительство ожидаемой субъектности новых поколений как суть государственной молодежной политики. Автор справедливо подчеркивает: «Конструирование реальности молодежью - объективный процесс раскрытия ее потенциалов, отражаемый тезаурусами как ориентационными комплексами и поддерживаемый ими» $(\Lambda y-$ ков, 2018с: 439).

Завершающая глава монографии посвящена перспективам исследований в области социологии. Она раскрывает такие непростые темы, как комплексное изучение человека в свете новых представлений о перспективах его развития, пограничные зоны человеческого существования в аспекте их понимания социологией. Здесь есть трактовки единой науки о человеке, в том числе с характеристикой междисциплинарности и трансдисциплинарности. Целый параграф посвящен гуманитарной экспертизе, которая в социологическом ракурсе еще не осмыслялась.

Как своего рода признание того, что более всего автор занимается проблематикой молодежи, в главе дана персоналия исследователей молодежи: от Руссо до наших дней (Иуков, 2018d: 344-495). Серия имен, идей, работ, которые здесь представлены, поначалу кажется приложением к основной теме (и задаче) автора. Но потом становится ясно, что определило желание В. А. Аукова от фрагментов тезаурусной социологии подняться к целостной ее теории. Подобную роль в монографии выполняет и перечень литературы, которая была использована при ее написании: примерно 2,5 тыс. работ в этом перечне свидетельствуют о многих годах вызревания концепции, которая представлена в книге «Тезаурусная социология».

\section{СПИСОК АИТЕРАТУРЫ}

Агранат, А. А. (2010) Социализация личности в военизированных организациях: проблемы нормы и отклонения. М. : Изд-во Моск. гуманит. ун-та. 228 с.

Болотин, И. С. (2009) Тезаурусы как инструмент преподавателя // Высшее образование в России. № 5. С. 169-172.

Болтенкова, Ю. В. (2011) Управленческие ресурсы устойчивого развития региональной службы занятости населения : автореф. дис. ... канд. социол. наук. М. 19 с.

Валерий Андреевич Ауков: концепции и исследования. Научные публикации (1966-2018) (2018) / сост. С. В. Иуков. М. : Изд-во Моск. гуманит. ун-та. 165 с.

Григорьев, С. И. (2010) Постмодернизм и социология в условиях кризиса // Социологические исследования. № 7. С. 136-142.

Ковалева, А. И., Аевичева, В. Ф. (2012/2013) О теориях молодежи и путях их развития // West-Ost-Report: Intern. Forum for Science and Research (Berlin). № 3/4. S. 97-101.

Костина, А. В. (2008) Тезаурусный подход как новая парадигма гуманитарного знания // Обсерватория культуры. №5. С. 102-109.

Кузнецова, Т. Ф. (2014) О концептуализации молодежи // Философские науки. № 12. C. 134-137.

Аамажаа, Ч. К. (2013) Тувиноведение: Новые горизонты. М. : Кн. дом « ИИБРОКОМ». 184 с.

Аапшин, В. А. (2013) Проблема человеческого потенциала молодежи и тезаурусный подход//Youth. World. Politics. № 1. C. 58-68.

Аосев, А. Ф. (1995) Форма. Стиль. Выражение. М. : Мысль. 944 с. 
Иуков, В. А. (2018а) Тезаурусная социология : в 4 т. М. : Изд-во Моск. гуманит. ун-та. Т. 1. 608 c. 2436

Ауков, В. А. (2018b) Тезаурусная социология : в 4 т. М. : Изд-во Моск. гуманит. ун-та. Т. 2. $576 \mathrm{c.}$

Ауков, В. А. (2018c) Тезаурусная социология : в 4 т. М. : Изд-во Моск. гуманит. ун-та. Т. 3. $608 \mathrm{c.}$

Иуков, В. А. (2018d) Тезаурусная социология : в 4 т. М. : Изд-во Моск. гуманит. ун-та. Т. 4. $640 \mathrm{c.}$

Ауков, В. А., Ауков, Вл. А. (2008) Тезаурусы: Субъектная организация гуманитарного знания. М. : ИзА-во Нац. ин-та бизнеса. 784 с.

Ауков, В. А., Ауков, Вл. А. (2013) Тезаурусы II: Тезаурусный подход к пониманию человека и его мира. М. : ИзА-во Нац. ин-та бизнеса. 640 с.

Ауков, В. А., Ауков, Вл. А. (2014) Методология тезаурусного подхода: стратегия понимания // Знание. Понимание. Умение. № 1. С. 18-35.

Погорский, Э. К. (2013) Молодежная политика как средство конструирования и развития инновационности молодежи // Youth. World. Politics. № 1. C. 37-49.

Социология молодежи: научная школа Московского гуманитарного университета: в 2 ч. (2018) / Ковалева А. И., Иуков Вал. А., Гневашева В. А., Иуков С. В. М. : ИзА-во Моск. гуманит. ун-та. Ч. 2. 508 с.

Чупров, В. И., Зубок, Ю. А. (2011) Социология молодежи. М. : Норма. 335 с.

Юдин, Б. Г. (2005) Курсанты в зеркале интересной социологии // Ауков Вал. А., Агранат А. А. Курсанты: Плац. Быт. Секс: Социол. и социальн.-психол. исследование. М. : Наука : Флинта. С. 3-7.

Aата поступления: 01.09.2019 2.

\section{THE FOUNDATION OF THESAURUS SOCIOLOGY \\ I. A. Poluekhtova \\ LOMONOSOV MOSCOW STATE UNIVERSITY}

A review of the publication: Lukov V. A. Thesaurus Sociology : 4 vol. M. : Moscow University for the Humanities Publ., 2018.

Keywords: review; theory of sociology; thesaurus approach

\section{REFERENCES}

Agranat, D. L. (2010) Sotsializatsiia lichnosti v voenizirovannykb organizatsiiakb: problemy normy $i$ otkloneniia. Moscow, Izd-vo Mosk. gumanit. un-ta. 228 p. (In Russ.)

Bolotin, I. S. (2009) Tezaurusy kak instrument prepodavatelia. Vysshee obrazovanie v Rossii, no. 5, pp. 169-172. (In Russ.)

Boltenkova, Iu. V. (2011) Upravlencheskie resursy ustoichivogo razvitiia regional' noi sluzbby zaniatosti naseleniia: Thesis of Diss. ... Candidate of Sociology. Moscow. 19 p. (In Russ.)

Valerii Andreevich Lukov: kontseptsii $i$ issledovaniia. Nauchnye publikatsii (1966-2018) (2018) / comp. by S. V. Lukov. Moscow, Izd-vo Mosk. gumanit. un-ta. 165 p. (In Russ.)

Grigor'ev, S. I. (2010) Postmodernizm i sotsiologiia v usloviiakh krizisa. Sotsiologicheskie issledovaniia, no. 7, pp. 136-142. (In Russ.)

Kovaleva, A. I. and Levicheva, V. F. (2012/2013) O teoriiakh molodezhi i putiakh ikh razvitiia. West-Ost-Report: Intern. Forum for Science and Research (Berlin), no. 3/4, pp. 97-101. (In Russ.)

Kostina, A. V. (2008) Tezaurusnyi podkhod kak novaia paradigma gumanitarnogo znaniia. Observatoriia kul'tury, no. 5, pp. 102-109. (In Russ.)

Kuznetsova, T. F. (2014) O kontseptualizatsii molodezhi. Filosofskie nauki, no. 12, pp. 134-137. (In Russ.)

Lamazhaa, Ch. K. (2013) Tuvinovedenie: Novye gorizonty. Moscow, Kn. dom «LIBROKOM». 184 p. (In Russ.) 
Lapshin, V. A. (2013) Problema chelovecheskogo potentsiala molodezhi i tezaurusnyi pod-khod. Youth. World. Politics, no. 1, pp. 58-68. (In Russ.)

Losev, A. F. (1995) Forma. Stil'. Vyrazhenie. Moscow, Mysl'. 944 p. (In Russ.)

Lukov, V. A. (2018a) Tezaurusnaia sotsiologiia: in 4 vol. Moscow, Izd-vo Mosk. gumanit. un-ta. Vol. 1.608 p. (In Russ.)

Lukov, V. A. (2018b) Tezaurusnaia sotsiologiia: in 4 vol. Moscow, Izd-vo Mosk. gumanit. un-ta. Vol. 2. 576 p. (In Russ.)

Lukov, V. A. (2018c) Tezaurusnaia sotsiologiia: in 4 vol. Moscow, Izd-vo Mosk. gumanit. un-ta. Vol. 3. 608 p. (In Russ.)

Lukov, V. A. (2018d) Tezaurusnaia sotsiologiia: in 4 vol. Moscow, Izd-vo Mosk. gumanit. un-ta. Vol. 4. 640 p. (In Russ.)

Lukov, V. A. and Lukov, Vl. A. (2008) Tezaurusy: Sube ktnaia organizatsiia gumanitarnogo znaniia. Moscow, Izd-vo Nats. in-ta biznesa. 784 p. (In Russ.)

Lukov, V. A. and Lukov, Vl. A. (2013) Tezaurusy II: Tezaurusnyi podkbod k ponimaniiu cheloveka $i$ ego mira. Moscow, Izd-vo Nats. in-ta biznesa. 640 p. (In Russ.)

Lukov, V. A. and Lukov, Vl. A. (2014) Metodologiia tezaurusnogo podkhoda: strategiia ponimaniia. Znanie. Ponimanie. Umenie, no. 1, pp. 18-35. (In Russ.)

Pogorskii, E. K. (2013) Molodezhnaia politika kak sredstvo konstruirovaniia i razvitiia innovatsionnosti molodezhi. Youth. World. Politics, no. 1, pp. 37-49.

Sotsiologiia molodezhi: nauchnaia shkola Moskovskogo gumanitarnogo universiteta: in 2 parts (2018) / Kovaleva A. I., Lukov Val. A., Gnevasheva V. A. and Lukov S. V. Moscow, Izd-vo Mosk. gumanit. un-ta. Part 2. 508 p. (In Russ.) Russ.)

Chuprov, V. I. and Zubok, Iu. A. (2011) Sotsiologiia molodezhi. Moscow, Norma. 335 p. (In

Yudin, B. G. (2005) Kursanty v zerkale interesnoi sotsiologii. In: Lukov Val. A. and Agranat D. L. Kursanty: Plats. Byt. Seks: Sotsiol. i sotsial'n.-psikbol. issledovanie. Moscow, Nauka, Flinta. Pp. 3-7.

Submission date: 01.09.2019.

Полуэхтова Ирина Анатольевна - доктор социологических наук, профессор, профессор кафедры теории и экономики средств массовой информации факультета журналистики Московского государственного университета им. М. В. Аомоносова; руководитель отдела социологических исследований Аепартамента аналитических исследований Новой сервисной компании (НСК). Адрес: 125009, Россия, г. Москва, ул. Моховая, д. 9, стр. 1. Тел.: +7 (495) 629-44-40. Эл. aspec: ipoluekhtova@gmail.com

Poluekhtova Irina Anatolyevna, Doctor of Socology, Professor, Professor, Department of Media Theory and Economics, Faculty of Journalism, Lomonosov Moscow State University; Head, Office of Social Research, Department of Analytical Research, New Service Company (NSC). Postal address: 9, Bldg. 1, Mokhovaya St., Moscow, Russian Federation, 125009. Tel.: +7 (495) 629-44-40. E-mail: ipoluekhtova@gmail.com 